\title{
Challenges in automated estimation of capillary refill time in dogs
}

Blaž Cugmas, Janis Spigulis

Blaž Cugmas, Janis Spigulis, "Challenges in automated estimation of capillary refill time in dogs," Proc. SPIE 10501, Optical Diagnostics and Sensing XVIII: Toward Point-of-Care Diagnostics, 1050117 (20 February 2018); doi: $10.1117 / 12.2284794$

SPIE. Event: SPIE BiOS, 2018, San Francisco, California, United States 


\title{
Challenges in automated estimation of capillary refill time in dogs
}

\author{
Blaž Cugmas*, Janis Spigulis \\ Biophotonics laboratory, Institute of Atomic Physics and Spectroscopy, University of Latvia, \\ 19 Raina Blvd., LV-1586, Riga, Latvia, EU
}

\begin{abstract}
Capillary refill time (CRT) is a part of the cardiorespiratory examination in dogs. Changes in CRT can reflect pathological conditions like shock or anemia. Visual CRT estimation has low repeatability; therefore, optical systems for automated estimation have recently appeared. Since existing systems are unsuitable for use in dogs, we designed a simple, small and portable device, which could be easily used at veterinary clinic. The device was preliminarily tested on several measurement sites in two dogs. Not all measurement sites were suitable for CRT measurements due to underlying tissue optical and mechanical properties. The CRT measurements were possible on the labial mucosa, above the sternum and on the digit where CRT was in the range of values, retrieved from the color video of the visual CRT measurement. It seems that light penetration predominantly governs tissue optical response when the pressure is applied. Therefore, it is important to select a proper light, which reaches only superficial capillaries and does not penetrate deeper. Blue or green light is probably suitable for light skin or mucosa, on the other hand, red or near-infrared might be used for skin with pigmented or thick epidermis. Additionally, further improvements of the device design are considered, like adding a calibrated spring, which would insure application of consistent pressure.
\end{abstract}

Keywords: Capillary refill time, veterinary medicine, dogs, monitoring, pulse oximeter, photoplethysmography

\section{INTRODUCTION}

The cardiorespiratory examination is a frequent procedure during the physical examination of dogs at veterinary clinics ${ }^{1}$. It includes the estimation of capillary refill time (CRT) which is one of the basic perfusion parameters ${ }^{2}$. The treating veterinarian presses on the gum above the canine tooth or on the labial mucosa in the dog's mouth which causes the tissue to pale. CRT is the time which is needed for the normal color to return. When estimated visually, normal canine CRT is between one and two seconds ${ }^{1}$. Prolonged CRT is a result of poor perfusion or peripheral vasoconstriction which can be caused by cold, shock, various cardiovascular diseases or anemia. On the other hand, short CRT reflects hyperdynamic status which can be a consequence of pain, fever, heat stroke, distributive shock etc.

In human medicine, CRT has been extensively studied. The parameter exhibits high specificity when related to mortality in children, so it can be used as a "red-flag" ". On the other hand, it has low sensitivity, so knowing that the CRT is normal, does not carry much diagnostic value. Moreover, CRT visual estimation, currently a routine procedure at veterinary clinics, has low repeatability ${ }^{4}$. The reason probably is because CRT estimation is not a standardized procedure ${ }^{3}$. It has been shown that CRT may be influenced by gender, temperature and the measurement site ${ }^{5}$. Also the intensity and time of applied pressure is an important factor ${ }^{6}$. It seems that CRT increases with the pressure duration and intensity.

Imaging and diffuse reflectance based optical systems for automated CRT estimation have recently appeared ${ }^{5,7-11}$. However, they are mostly unsuitable for the use in dogs. Most of the procedures ${ }^{5,9-11}$ require several seconds of patient stillness which is hard to achieve in veterinary practice. When CRT is estimated from imaging methods ${ }^{5}, \operatorname{dog}$ hairiness and dark skin can be problematic. This can be solved by measuring CRT on oral mucosa, which is usually pink. However, most of the available systems are too large to be suitable for measurements in the dog's mouth ${ }^{9-11}$.

Therefore, we propose a simple, small and portable device which could be easily used at the clinic on several measurement sites. The device is based on the optical reflectance of three wavelengths (green, red and near-infrared NIR) which would insure sufficient optical sampling depth in case of extensive skin pigmentation. The device was preliminarily tested by a veterinarian on two dogs in the clinical environment.

*blaz.cugmas@lu.lv; phone+37167228249; http://www.asi.lv/

Optical Diagnostics and Sensing XVIII: Toward Point-of-Care Diagnostics, edited by Gerard L. Coté, Proc. of SPIE Vol. 10501, 1050117 - (c) 2018 SPIE · CCC code:

$1605-7422 / 18 / \$ 18 \cdot$ doi: $10.1117 / 12.2284794$ 


\section{DEVICE}

The optical device (Fig. 1) is small and portable so that it can be easily placed next to the animal without the need for an additional stand. It is powered by a standard $9 \mathrm{~V}$ battery. The optical sensor with sampling frequency of $132.4 \mathrm{~Hz}$ is situated on a flexible arm which enables measurements on hardly accessed sites, e.g. dog's mouth. The sensor MAX30105 (Maxim Integrated, USA) is integrated on the commercially available breakout board $(2.36 \mathrm{~cm} \times 2.06 \mathrm{~cm}$, SEN-14045, SparkFun Electronics, USA). The optical sensor is comprised of three LEDs; green (peak wavelength - PW $=537 \mathrm{~nm}$, full width at half maximum $-\mathrm{FWHM}=35 \mathrm{~nm})$, red $(\mathrm{PW}=660 \mathrm{~nm}, \mathrm{FWHM}=20 \mathrm{~nm})$ and near-infrared (NIR) $(\mathrm{PW}=880 \mathrm{~nm}, \mathrm{FWHM}=30 \mathrm{~nm})$. On the reverse side of the sensor, a force resistor (FSR-402, Interlink Electronics, USA) is placed in the voltage divider circuit together with $3.3 \mathrm{k} \Omega$ resistor in order to detect applied pressure. The whole sensor is connected to the microcontroller (Pro Micro 5V/16MHz, SparkFun Electronics) by the insulated and flexible cable allowing all measurement sites to be reached. Acquired data is stored with data logger (DEV-13712, SparkFun Electronics) suitable for micro SD cards. All components are safely stored in the insulated and waterproof box $(11.4 \times 11.3 \times 5.7 \mathrm{~cm})$.

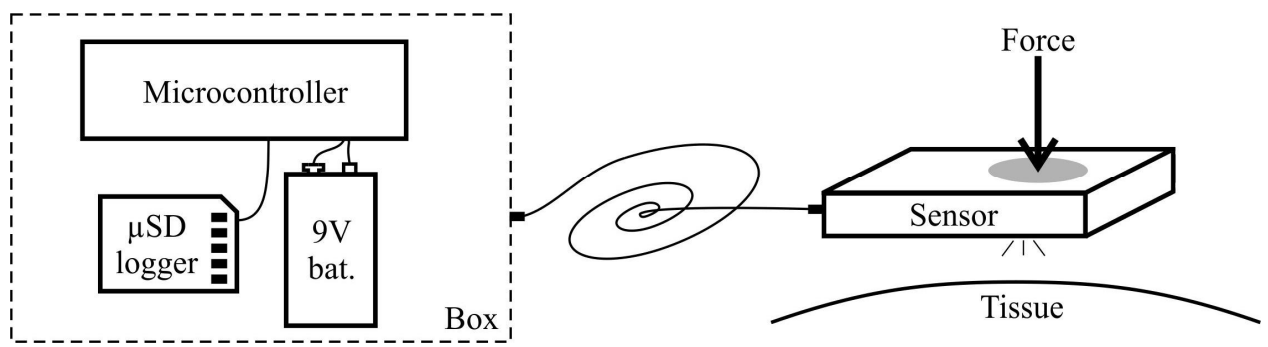

Figure 1. Diagram of the prototype device.

\section{CRT MEASUREMENTS}

The device was preliminarily tested on two dogs; a Dachshund and a Labrador with the body masses of 10 and $35 \mathrm{~kg}$, respectively. Measurements were done during the scheduled dental cleaning procedure while the animals were under general anesthesia. According to the Latvian national laws and European directive 2010/63/EU, all measurements were led by a nationally certified veterinarian and owners written permission for the CRT measurement was obtained. Beside two standard sites, we opted to test several new and easily reachable measurement sites:

- labial mucosa inside the mouth,

- gum above the canine tooth,

- skin of ear pinna,

- skin above the sternum's xiphoid process,

- $\quad$ skin above the metacarpal bones, close to carpal pad (proximal and palmar side),

- $\quad$ skin above the metacarpal bones, next to metacarpal pad (distal and palmar side),

- metacarpal pad,

- front leg digit (medial side),

- perineum,

- skin above caudal vertebrae (on the tail), close to anal area (ventral side).

The sensor was gently pressed against the tissue. After good coupling was reached, the operator pressed with the index finger on the force sensor for around two seconds in the same manner as it is done during visual CRT estimation procedure ${ }^{1}$. When the pressure was released, the operator ensured that the sensor stayed in good contact with the tissue. Three measurements were obtained at each site. After measurements were performed, the veterinarian visually estimated CRT by pressing on the gum or the labial mucosa. The manual procedure was additionally recorded by the commercial RGB camera ( $\alpha 5100$, Sony, Japan). By slowly studying the acquired video ( $25 \mathrm{fps})$ CRT was calculated as the difference between two events: (1) when the veterinarian's finger stopped pressing and started lifting, and (2) when the tissue (gum or labial mucosa) returned to the normal red shade (video RGB values returned to the initial values). 
CRT-related changes in force and optical sensor readings were regarded as so-called signal transitions. The starting and the ending time points (Fig. 2) of optical $\left(t_{s 3}, t_{s 4}\right)$ and pressure $\left(t_{p 1}, t_{p 2}, t_{p 3}, t_{p 4}\right)$ signal transitions were calculated with $10 \%$ and $90 \%$ reference levels, based on the risetime and falltime functions (Matlab R2015a, MathWorks Inc, USA). The pressure application duration $\left(t_{p r e s}\right)$ was estimated as a difference between $t_{p 1}$ and $t_{p 3}$. The interval between $t_{p 2}$ and $t_{p 3}$ served for the calculation of the average applied pressure. Finally, CRT was estimated (Fig. 2) as:

$$
C R T=t_{\text {delay }}+t_{\text {fall }}=\left(t_{s 3}-t_{p 3}\right)+\left(t_{s 4}-t_{s 3}\right)=t_{s 4}-t_{p 3},
$$

where $t_{\text {delay }}$ is the delay between the starting points of optical and pressure signal fall and $t_{\text {fall }}$ is a true fall time of the optical signal. Standard error (SE) was calculated as a quotient of standard deviation and the square root of 3 (due to three repetitions).

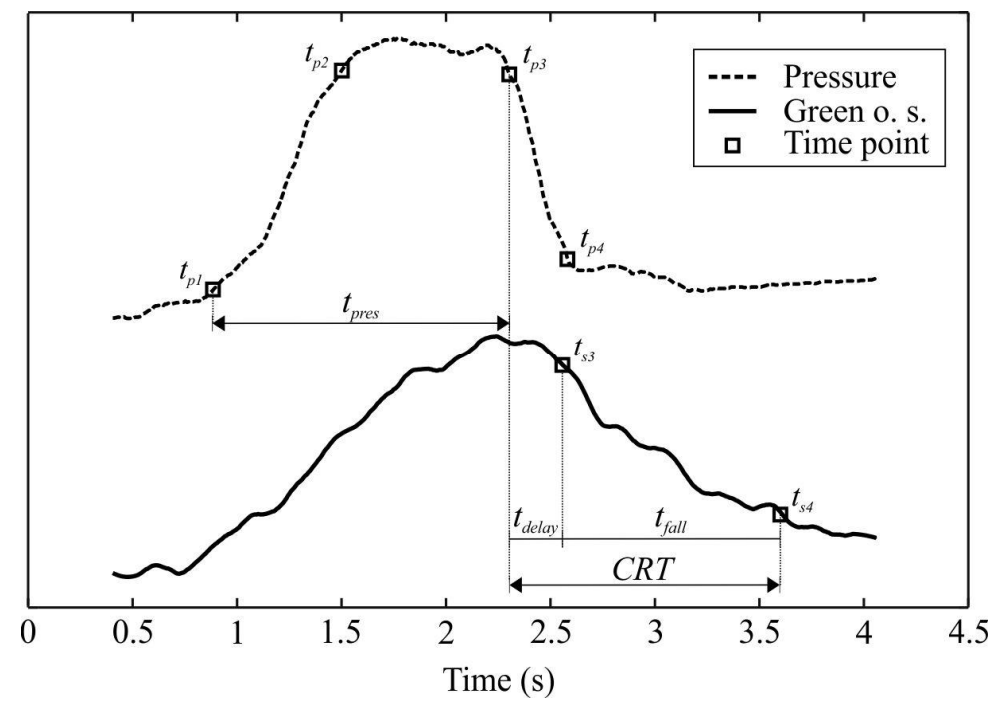

Figure 2. The pressure and green optical signal ("Green o.s.") with starting and ending time points of their transitions.

\section{RESULTS AND DISCUSSION}

The new device was tested on two dogs (Table 1). For both dogs, the veterinarian (V) estimated CRT was of 1 second. The approach with camera $(\mathrm{C})$ resulted in lower CRT values, i.e. $0.84 \mathrm{~s}$ and $0.65 \mathrm{~s}$. When the new device was tested, not all measurement sites appeared suitable for CRT measurements. The measurements were possible on the labial mucosa, above the sternum, on the digit and partially on the distal metacarpus and on the tail (Table 1). For dog 1, CRT values ranged from 0.47 to $0.75 \mathrm{~s}$. The second dog's CRT was between 0.61 and $0.71 \mathrm{~s}$. In both cases, CRT estimation on labial mucosa was well in agreement with the results of the approach with camera. This is somehow expected since camera readings were taken from the same measurement site.

Table 1. CRT with standard error (SE) on different measurement sites. The direction of signal transition is marked with arrows.

\begin{tabular}{c|cccc|cccc} 
& \multicolumn{4}{|c|}{$\operatorname{Dog} 1(\mathrm{~V}=1 \mathrm{~s}, \mathrm{C}=0.84 \mathrm{~s})$} & \multicolumn{4}{c}{$\operatorname{Dog} 2(\mathrm{~V}=1 \mathrm{~s}, \mathrm{C}=0.65 \mathrm{~s})$} \\
\hline Site & Dir. & CRT $(\mathrm{SE})$ & Pressure & Pres. time & Dir. & CRT $(\mathrm{SE})$ & Pressure & \multicolumn{2}{c}{ Pres. time } \\
& & {$[\mathrm{s}]$} & {$[\mathrm{N}]$} & {$[\mathrm{s}]$} & & {$[\mathrm{N}]$} & {$[\mathrm{s}]$} \\
\hline Labial mucosa & $\downarrow$ & $0.80^{\mathrm{g}}(0.06)$ & 3.93 & 1.16 & $\downarrow$ & $0.61^{\mathrm{g}}(0.06)$ & 4.67 & 1.28 \\
Sternum & $\uparrow$ & $0.52^{\mathrm{r}}(0.05)$ & 7.32 & 1.70 & $\uparrow$ & $0.71^{\mathrm{g}}(0.14)$ & 8.30 & 1.98 \\
Metacarp. dist. & $\downarrow$ & $0.56^{\mathrm{r}}(0.04)$ & 18.91 & 1.55 & & \multicolumn{3}{c}{ (failed measurement) } \\
Finger & $\uparrow$ & $0.47^{\mathrm{r}}(0.02)$ & 2.70 & 1.44 & $\uparrow$ & $0.64^{\mathrm{r}}(0.14)$ & 9.21 & 1.69 \\
Tail & $\downarrow$ & $0.52^{\mathrm{g}}(0.01)$ & 5.15 & 1.56 & \multicolumn{4}{c}{ (failed measurement) } \\
\hline
\end{tabular}

green channel, ${ }^{\mathrm{r}}$ red channel 
Some measurement sites did not prove suitable for CRT measurements with our device. For example, the sensor's flat surface did not fit well on the round gum surface which resulted in many motion artifacts in the optical signal. Furthermore, gum indentation was minimal because the tissue lies directly above the canine tooth which made applying stable pressure very challenging. On the other hand, the perineum was soft and consequently, the tissue did not offer enough resistance to squeeze the blood out of the capillaries. Ear pinna seemed too thin for stable reflectance measurements. Probably, a transmittance approach would be more suitable for this measurement site.

Another important issue is the light wavelength selection which affects penetration depth. Recent studies have opted for blue $^{8}$ or for a combination of green, red and NIR light ${ }^{10}$. The latter is available with most of the commercially available optical pulse sensors. Since canine skin and mucosa can be rich with highly absorbing melanin, we have opted for the sensor with larger sampling depth.

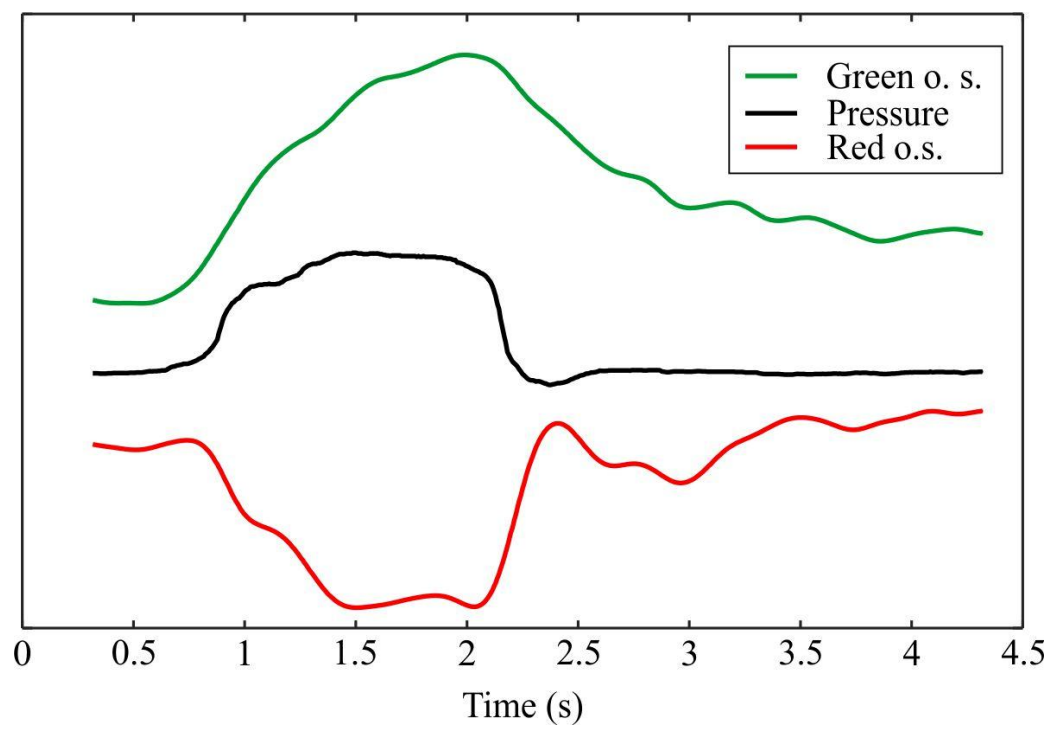

Figure 3. CRT measurement on the labial mucosa. When the pressure was applied, opposite signal transition directions of the green and red channel appeared.

It seems that light penetration predominantly governs the tissue optical response when the pressure is applied. On some measurement sites, the light of certain wavelengths penetrated deep enough to reach larger veins and underlying tissues (e.g. muscles). Additionally, there is an increased probability that the light was reflected from the underlying bone. The literature ${ }^{12,13}$ shows that green, red and NIR light might be detected if fully reflected from the depth of $2.5 \mathrm{~mm}, 6.7 \mathrm{~mm}$ and $12.0 \mathrm{~mm}$, respectively. For example, the thickness of canine buccal epithelium ${ }^{14}$ and subepithelial layer ${ }^{15}$ is $0.2 \mathrm{~mm}$ and $2.1 \mathrm{~mm}$, respectively. Therefore, the light used in this study could easily reach the alveolar bone which was reflected in different optical responses on the same measurement site (Fig. 3). It seems important to select light with appropriate wavelength which only reaches superficial capillaries and does not penetrate deeper.

Unfortunately, it is difficult to comply with this conclusion when building universal CRT device for all dog types (color and size variations) and measurement sites (tissue structure variations). Firstly, these variations resulted in different signal transition directions, even from the same measurement (Fig. 3, Table 1). The same phenomenon was reported in humans, where reflectance responded uniquely to applied pressure ${ }^{16}$. In the humane studies, the transitional signal rose in one study ${ }^{8}$ but fell in the another ${ }^{10}$. Secondly, the green light was heavily absorbed at some measurement sites (especially with the first $\operatorname{dog}$ ). Therefore, red light measurements were used. On the other hand, as stressed in the previous paragraph, the red light would be unsuitable for the use on thin and bright measurement sites (e.g. gum). 


\section{CONCLUSION}

In this study, we proposed a new device, adopted for automated CRT measurements in dogs. The device was successfully tested on two dogs by a veterinarian in the clinical environment. Measured CRT was similar to the reference CRT value, estimated from the RGB camera video. Conversely, visual estimation proved very imprecise. The best measurement sites were on the labial mucosa, above the sternum and on the digit. However, due to the device design and the choice of light and measurement site, the CRT measurements were not successful in all cases. Therefore, further improvements of the device design are considered. For example, the addition of a calibrated spring which would guarantee a permanent control of the applied pressure.

\section{ACKNOWLEDGMENTS}

The study was supported by the Marie Skłodowska-Curie actions of the European Union (IF, DogSPEC, 745396). We would also like to express our gratitude to veterinarians Eva Štruc, Liene Dindone, Alla Olivrī, Solvita Buivide and all other personnel from Animal Health Centre, Riga (Dzīvnieku veselības centrs, Rīga, Latvia) for all the help and technical support.

\section{REFERENCES}

[1] Bexfield, N. and Lee, K., [BSAVA Guide to Procedures in Small Animal Practice], British Small Animal Veterinary Association, Gloucester, 67 (2010).

[2] "Primary Survey (Triage) and Resuscitation - Emergency Medicine and Critical Care.", Merck Vet. Man., $<$ http://www.merckvetmanual.com/emergency-medicine-and-critical-care/evaluation-and-initial-treatment-of-theemergency-patient/primary-survey-triage-and-resuscitation> (30 November 2017).

[3] Fleming, S., Gill, P., Jones, C., Taylor, J. A., Van den Bruel, A., Heneghan, C., Roberts, N. and Thompson, M., "The Diagnostic Value of Capillary Refill Time for Detecting Serious Illness in Children: A Systematic Review and Meta-Analysis," PLoS ONE 10(9), e0138155 (2015).

[4] Pickard, A., Stinson, J., Cooke, E., Myers, D., Karlen, W. and Ansermino, J. M., "Intra-observer and interobserver repeatability of capillary refill time," Anaesthesia 67, 44 (2012).

[5] John, R. T., Henricson, J., Nilsson, G. E., Wilhelms, D. and Anderson, C. D., "Reflectance spectroscopy: to shed new light on the capillary refill test," J. Biophotonics, 1-9 (2017).

[6] Pickard, A., Karlen, W. and Ansermino, J. M., "Capillary Refill Time: Is It Still a Useful Clinical Sign?,” Anesth. Analg. 113(1), 120-123 (2011).

[7] Shavit, I., Brant, R., Nijssen-Jordan, C., Galbraith, R. and Johnson, D. W., “A Novel Imaging Technique to Measure Capillary-Refill Time: Improving Diagnostic Accuracy for Dehydration in Young Children With Gastroenteritis," Pediatrics 118(6), 2402 (2006).

[8] Kviesis-Kipge, E., Curkste, E., Spigulis, J. and Eihvalde, L., "Real-time analysis of skin capillary-refill processes using blue LED," Proc. SPIE 7715, 771523 (2010).

[9] Shamsudin, N., "A Device for Measurement of Capillary Refilling Time," Master's thesis (2012).

[10] Blaxter, L. L., Morris, D. E., Crowe, J. A., Henry, C., Hill, S., Sharkey, D., Vyas, H. and Hayes-Gill, B. R., “An automated quasi-continuous capillary refill timing device," Physiol. Meas. 37(1), 83 (2016).

[11] Faezeh Talebi Liasi, Ravikant Samatham and Steven L. Jacques., "Noninvasive in vivo optical characterization of blood flow and oxygen consumption in the superficial plexus of skin," J. Biomed. Opt. 22(11), 115002 (2017).

[12] Kohen, E., Santus, R. and Hirschberg, J. G., [Photobiology], Elsevier Science, San Diego, 308 (1995).

[13] Bashkatov, A. N., Genina, E. A., Kochubey, V. I. and Tuchin, V. V., "Optical properties of human skin, subcutaneous and mucous tissues in the wavelength range from 400 to $2000 \mathrm{~nm}$," J. Phys. -Appl. Phys. 38(15), 2543-2555 (2005).

[14] Sa, G., Xiong, X., Wu, T., Yang, J., He, S. and Zhao, Y., "Histological features of oral epithelium in seven animal species: As a reference for selecting animal models," Eur. J. Pharm. Sci. 81(Supplement C), 10-17 (2016).

[15] Perenack, J., Wood, R. J., Block, M. S. and Gardiner, D., "Determination of subepithelial connective tissue graft thickness in the dog," J. Oral Maxillofac. Surg. 60(4), 415-421 (2002).

[16] Cugmas, B., Bregar, M., Bürmen, M., Pernuš, F. and Likar, B., "Impact of contact pressure-induced spectral changes on soft-tissue classification in diffuse reflectance spectroscopy: problems and solutions," J. Biomed. Opt. 19(3), 037002 (2014). 